\title{
A legislação e a gestão para redução de riscos relacionados a inundações no município de São Paulo/SP
}

\author{
Legislation and management for risks reduction related to floods in São \\ Paulo/SP, Brazil
}

\author{
Rosangela do Amaral1(i) \\ Jurandyr Luciano Sanches Ross ${ }^{2}$ (D)
}

\author{
Palavras-chave: \\ Gestão de riscos \\ Inundação \\ Legislação ambiental
}

\begin{abstract}
Resumo
As inundações em áreas urbanas causam problemas relacionados ao tráfego, prejuízos e danos em áreas comerciais e residenciais. Historicamente, apesar de diversas legislações ambientais restringirem o uso das planícies fluviais, muitas dessas áreas foram ocupadas e regularizadas perante os governos locais. A imprecisão e sobreposição das leis também facilitaram interpretações errôneas e infrações. Esse artigo tem como objetivo analisar os instrumentos de gestão de riscos previstos na legislação brasileira e sua aplicação em áreas recorrentemente atingidas por inundações. $\mathrm{O}$ estudo de caso foi aplicado à Bacia do Córrego Ipiranga, em São Paulo/SP, onde foram constatados 82 eventos de inundação em um período de 52 anos, predominantemente no período entre 2010 e 2017, com registro de danos humanos, materiais e econômicos. Diversas medidas estruturais foram empregadas até o momento, mas não tiveram eficácias suficientes para solucionar os problemas. Embora algumas leis indiquem readequações de uso nos espaços atingidos pelas inundações, essas mudanças raramente ocorrem. Observase que ao longo do tempo, a legislação que envolve o fenômeno da inundação apresenta uma mudança de paradigma, onde o foco, inicialmente voltado à proteção ambiental das áreas de preservação permanente, migra para a gestão de riscos de desastres.
\end{abstract}

\begin{abstract}
Flooding in urban areas causes problems related to traffic, damage in businesses and homes. Historically, although several environmental laws have restricted the use of river plains, many of these areas have been occupied and regularized by local governments. Inaccuracy and overlapping of laws also facilitated misinterpretations and violations. This article aims to analyze the risk management instruments provided for in Brazilian legislation
\end{abstract}

\footnotetext{
1 Doutoranda pelo programa de Pós Graduação em Geografia Física do Departamento de Geografia, Faculdade de Filosofia, Letras e Ciências Humanas da Universidade de São Paulo e pesquisadora científica do Instituto Geológico, Secretaria de Infraestrutura e Meio Ambiente, Governo do Estado de São Paulo. roamaral@sp.gov.br

2 Professor Doutor do programa de Pós Graduação em Geografia Física do Departamento de Geografia, Faculdade de Filosofia, Letras e Ciências Humanas da Universidade de São Paulo. juraross@usp.br
} 
and their application in areas frequently affected by floods. The case study was applied to the Ipiranga Stream Basin, in São Paulo / SP, where occurred 82 flood events were observed over a 52 -year period, predominantly between 2010 and 2017, with human, material and economic damage. The various structural measures employed so far have not been sufficient to solve the problems. Although some laws indicate readjustments of use in areas affected by floods, but these changes rarely occur. It is observed that over time, the legislation that involves the phenomenon of flooding presents a paradigm shift, where the initial focus on environmental protection of the areas of permanent preservation, migrates to disaster risk management.

\section{INTRODUÇÃO}

As inundações representam o desastre natural que ocorre com maior frequência no mundo, e causam prejuízos humanos (mortos e desabrigados) e financeiros. Segundo dados de Swiss RE Institute (2017), o registro de 327 desastres naturais que ocorreram no mundo em 2016 revelou que o total de perdas econômicas superou os dados registrados desde 2012, revertendo a tendência de decréscimo do período. As perdas econômicas foram da ordem de USD 175 bilhões, quase o dobro do registrado em 2015. Em relação aos dados sociais, cerca de 11 mil pessoas perderam a vida ou desapareceram na ocorrência desses desastres.

As inundações são consideradas desastres naturais quando causam uma perturbação no funcionamento habitual de uma comunidade ou sociedade em qualquer escala, e criam condições de exposição e vulnerabilidade, com perdas e impactos humanos, materiais, econômicos e ambientais (UNISDR, 2017).

Esse artigo tem como objetivo avaliar os instrumentos de controle e gestão de riscos previstos na legislação e sua aplicação em áreas recorrentemente atingidas por inundações.

Ao longo do período analisado, o foco da legislação relacionada à inundação migrou lentamente da proteção ambiental para a gestão dos riscos associados aos desastres.

A Região Metropolitana de São Paulo (RMSP) apresenta, anualmente, sobretudo no verão, sérios problemas relacionados com inundações em vias marginais aos rios e córregos, interrompendo o fluxo de veículos, além de residências, comércios e indústrias localizadas próximas aos cursos d'água que são atingidos.

Em revisões bibliográficas encontram-se diversas conceituações para inundação. Para este trabalho, optou-se por adotar que inundação representa o transbordamento das águas de um curso d'água, atingindo a planície de inundação ou área de várzea (CARVALHO; MACEDO; OGURA, 2007; AMARAL; RIBEIRO, 2009). Não estão contempladas nessa análise as ocorrências de enchentes, que são definidas pela elevação do nível d'água no canal de drenagem, devido ao aumento da vazão, atingindo a cota máxima do canal, porém, sem extravasar. Também não serão considerados na análise os alagamentos, que representam um acúmulo momentâneo de águas em determinados locais por deficiência no sistema de drenagem e não são relacionados à dinâmica dos cursos d'água.

Apesar de existência de leis que restringem o uso das planícies fluviais em diversas esferas de poder, muitas dessas áreas foram ocupadas e estão regulares perante os municípios, com cobranças de impostos e demais deveres, além da disponibilização de serviços básicos, como instalação de sistemas de água e energia elétrica. Porém, não há auxílio ou reconhecimento para o abatimento dos impostos quando os eventos de inundação atingem esses imóveis.

Como estudo de caso será retratada a Bacia do Córrego Ipiranga, localizada na zona sul do Município de São Paulo, que apresenta anualmente inundações. Sua extensão aproximada é de $11 \mathrm{~km}$ e sua área de contribuição corresponde a $23 \mathrm{~km}^{2}$. Deste total, cerca de $80 \%$ está urbanizado e os $20 \%$ restantes são representados pelo remanescente de Mata Atlântica do Parque Estadual Fontes do Ipiranga (PEFI), onde está localizada grande parte das nascentes do córrego (Figura 1). 
Figura 1 - Localização da Bacia do Córrego Ipiranga, Município de São Paulo/SP.
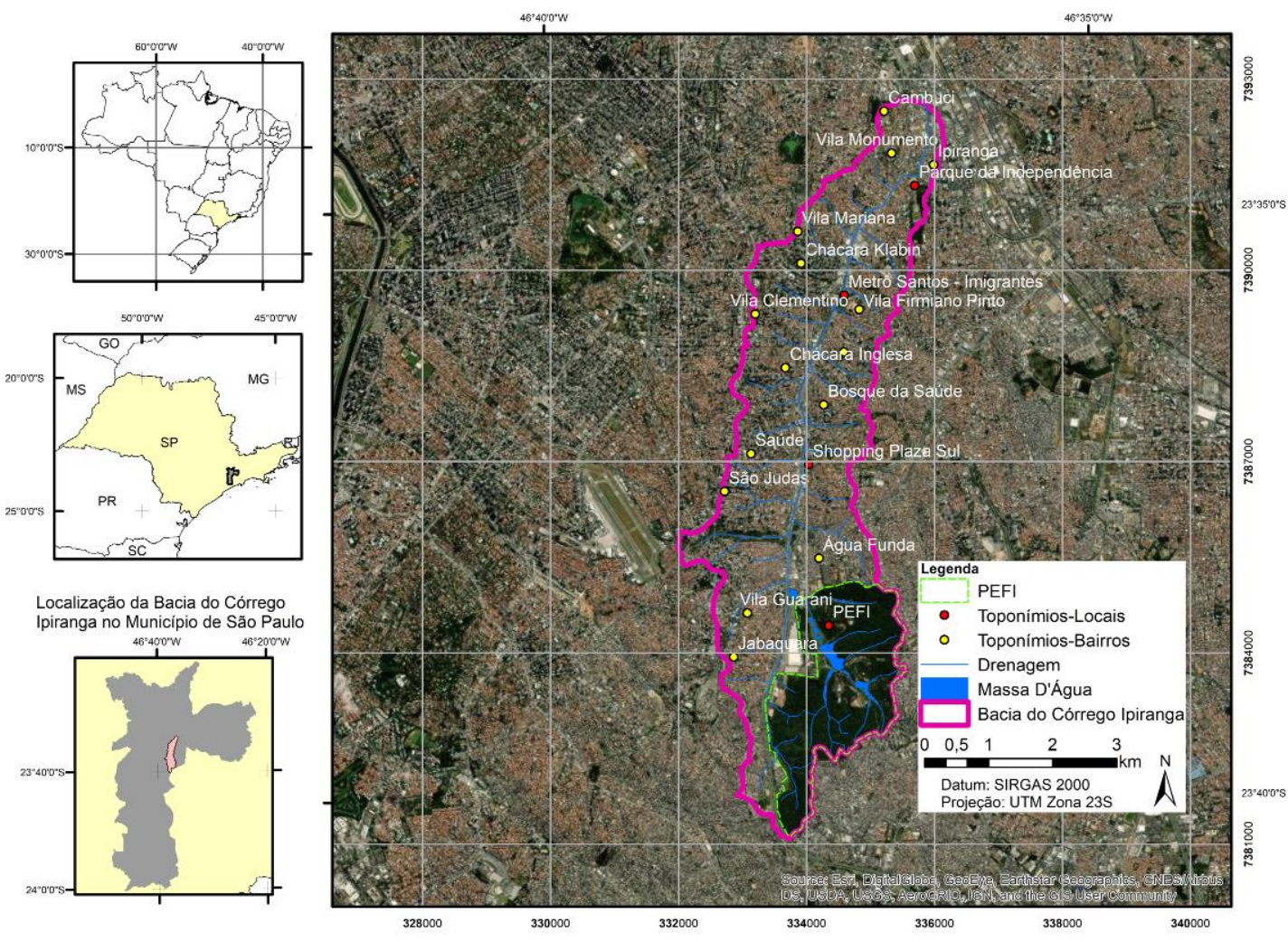

Org: Autores, 2019.

\section{CONTEXTO DAS LEGISLAÇÕES VIGENTES}

A utilização de áreas de várzea é histórica e está ligada à grande dificuldade de deslocamento e escoamento de mercadorias no passado, quando se utilizava o rio como meio de transporte principal. Os rios também eram utilizados para obtenção de água para consumo e áreas de cultivo, bem como para disposição de dejetos. Assim, as cidades se desenvolveram preferencialmente às margens dos rios e no litoral. A área a ser ocupada dependia da memória dos habitantes locais em relação à extensão e frequência com que as inundações ocorriam. Uma sequência de anos sem ocorrência de inundações constituía motivo para a sociedade avançar a ocupação nas planícies. (TUCCI, 1995; 2002; 2003; TAVARES; SILVA, 2008).

A Lei Federal $\mathrm{n}^{0}$ 4.771/1965 - Código Florestal (BRASIL, 1965) determinava que as áreas ao longo dos cursos d'água eram destinadas para preservação permanente, e, obviamente, impróprias para a urbanização.

Entretanto, o não cumprimento da lei deu origem a incontáveis áreas sujeitas à inundação, e, consequentemente, aos riscos a que estão expostos seus habitantes. Da mesma forma, as áreas que foram ocupadas em período anterior a essa data tornaram-se passivos ambientais, ou seja, áreas que deveriam ter passado por um processo de readequação para atendimento à legislação ambiental promulgada, o que não ocorreu.

Em São Paulo, o processo de ocupação das áreas de várzeas se iniciou na década de 1930, com a retificação do Rio Tietê, para futura implantação das avenidas marginais e aproveitamento das áreas centrais, com motivação nas questões de saneamento e salubridade; logo depois ocorre a retificação do rio Pinheiros, para condução das águas para Usina Henry Borden com a finalidade de gerar energia elétrica. Como consequência, as retificações liberaram as áreas de várzeas e meandros aterrados para empreendimentos imobiliários. Posteriormente, com o Plano de Avenidas, na década de 1950, esse modelo foi adotado em outras áreas. Na década de 1970, as várzeas e os fundos de vale foram institucionalizados como eixos de expansão da urbanização pelos governos da época. Desta forma, a ocupação das áreas das planícies de inundação dos cursos d'água não foi fruto apenas da ocupação desordenada, mas também de uma ação de incentivos políticos para 
empreendimentos imobiliários e para a instalação de importantes sistemas viários (SEABRA, 1987; ROLNIK, 1999; CUSTÓDIO, 2002; TRAVASSOS, 2004; KANASHIRO, 2013; ANELLI, 2015).

Todas essas intervenções, aliadas ao vertiginoso crescimento da população, causaram os problemas atuais do ordenamento territorial urbano quanto à gestão dos cursos d'água e planícies, principalmente ligados ao risco de inundações e preservação dos recursos hídricos (RODRIGUES, 2015).

Após a demanda de ocupação das várzeas na década de 1970, diversas outras legislações reafirmaram a inadequação da ocupação dessas áreas do ponto de vista ambiental, sujeitas a diversas sanções. Entretanto, contradições e divergências foram se acumulando na sobreposição de leis, conforme apontado por Travassos (2004) e Rodrigues (2015).

A Lei Federal n 6.766/1979 - Lei Lehmann (BRASIL, 1979), que tratava das questões relativas ao parcelamento do solo urbano, afirmava que ao longo das águas correntes e dormentes era obrigatória uma faixa não edificável de 15 metros de cada lado. Com essa nova definição criou-se uma disparidade com o Código Florestal, que estabelecia faixas de proteção de 30 metros ao longo dos cursos d'água, e surge a dúvida sobre a aplicação diferenciada das leis em áreas rurais e urbanas.

A Lei Federal n 6.938/1981 (BRASIL, 1981), que dispõe sobre a Política Nacional do Meio Ambiente, prevê no seu Art. $4^{\circ}$, dentre alguns de seus objetivos a preservação e restauração dos recursos ambientais para a manutenção do equilíbrio ecológico propício à vida e a imposição ao poluidor e ao predador, da obrigação de recuperar e/ou indenizar os danos causados ao equilíbrio ecológico.

A Lei Federal nº 9.605/1998 (BRASIL, 1998) considera como crime ambiental (Art. 38) a destruição ou danos à floresta considerada de preservação permanente, mesmo que em formação, ou utilizá-la com infringência das normas de proteção. $\mathrm{O}$ crime é sujeito à detenção ou multa, ou ambas cumulativamente.

A Resolução CONAMA nº 303/2002 (BRASIL, 2002) reforça a importância do que já havia sido estabelecido pelo Código Florestal e considera as áreas de preservação permanente como instrumentos de relevante interesse ambiental, que integram o desenvolvimento sustentável, sem diferenciar a aplicação da legislação em áreas urbanas ou rurais.

Mas ainda assim, as áreas marginais aos cursos d'água continuaram a ser ocupadas, e em muitos casos, regularizadas ilegalmente pelos governos municipais. Então, as leis se voltaram à gestão dos riscos já estabelecidos e não mais numa perspectiva de proteção ambiental e prevenção às populações ribeirinhas.

Com a ocupação das planícies fluviais, um importante serviço ambiental é afetado: o amortecimento das vazões extremas. Esse serviço ambiental vem sendo substituído por medidas estruturais, como a construção de piscinões, em substituição às funcionalidades hidrológicas naturais (RODRIGUES, 2015).

Pesquisas mostram que as ações estruturais são necessárias, mas não suficientes para reduzir os danos relacionados às inundações. Há necessidade de que essas medidas sejam implantadas em conjunto com as medidas não estruturais e que a população desenvolva uma resiliência aos desastres, isto é, a capacidade de reagir coletivamente, de tal modo que os impactos socioeconômicos de um desastre sejam os mínimos possíveis. Por outro lado, observa-se que a atuação dos órgãos de defesa civil vem mudando lentamente da administração dos desastres para a gestão de riscos, por ser essa abordagem mais efetiva, uma vez que age-se antes do desastre ocorrer, poupando vidas e bens (CUNHA, 2012; JHA; BLOCH; LAMOND, 2012).

Compreender os tipos e as causas das inundações, as probabilidades de ocorrência, seu impacto em termos de extensão, duração, profundidade (altura da massa d'água em metros) e velocidade é essencial para o planejamento de medidas e soluções. Também é importante conhecer a frequência das inundações, as características da população que ocupa as áreas potencialmente afetadas e o seu grau de vulnerabilidade. Isso é crítico para definir a necessidade, urgência e prioridade em implantar as medidas de gestão de risco de inundação (JHA; BLOCH; LAMOND, 2012).

De acordo com a Lei Federal n ${ }^{\circ} 12.608 / 2012$ (BRASIL, 2012), que institui a Política Nacional de Proteção e Defesa Civil (PNPDEC), é dever da União, Estados e Municípios adotarem as medidas necessárias à redução dos riscos de desastres. Essa política contempla uma abordagem sistêmica de ações de prevenção, mitigação, preparação, resposta e recuperação a desastres voltada à proteção e defesa civil. A lei recomenda que quando o risco estiver relacionado à inundação, as pesquisas devem adotar a bacia hidrográfica como unidade de análise.

No âmbito do Estado de São Paulo, a Lei Estadual no 13.798/2009 - Política Estadual de 
Mudanças Climáticas (PEMC) (SÃO PAULO ESTADO, 2009) estabelece princípios, diretrizes e instrumentos a ser adotados pelos órgãos governamentais para garantir o desenvolvimento sustentável e o disciplinamento do uso do solo por meio do Zoneamento Econômico Ecológico (ZEE) e a resposta a eventos climáticos extremos que possam causar calamidade pública, identificando e mapeando as vulnerabilidades existentes nos municípios, de forma a servir como base para políticas de adaptação aos impactos das mudanças climáticas.

O Decreto Estadual $\mathrm{n}^{0} 57.512 / 2011$ (SÃO PAULO - ESTADO, 2011) que institui o Programa Estadual de Prevenção de Desastres Naturais e Redução de Riscos Geológicos (PDN), também busca articular estratégias e ações executivas das diversas instâncias e instituições estaduais com atribuições ou com capacitação para atuar nas várias etapas e atividades necessárias à prevenção de desastres naturais.

Alguns instrumentos são utilizados na prevenção e mitigação de riscos. Brollo e Ferreira (2016) discorreram sobre os principais instrumentos que vêm sendo sistematicamente aplicados e monitorados no Estado de São Paulo e as especificidades de cada um:

a) Mapeamentos de áreas de risco a escorregamentos, inundações e erosão. Esses estudos se iniciaram em 2003 com o objetivo de minimizar e prevenir acidentes e desastres e oferecem recomendações ao poder municipal para reduzir danos sociais e econômicos.

b) Plano Municipal de Redução de Riscos (PMRR). Esses planos são elaborados desde 2004 pelas prefeituras, segundo os princípios do Ministério das Cidades.

O trabalho do PMRR envolve: I) o treinamento dos agentes municipais para elaboração de diagnóstico, prevenção e gerenciamento de risco, incluindo o mapeamento das áreas de risco nas áreas de ocupação irregular do município; II) o apoio financeiro ao município para elaboração do plano de redução de risco. Este instrumento de planejamento contempla o diagnóstico de risco, as medidas de segurança necessárias, a estimativa de recursos necessários, o estabelecimento de prioridades e compatibilização com os programas de urbanização de favelas e regularização fundiária; e III) apoio financeiro para elaboração de projetos de contenção de encostas em áreas de risco consideradas prioritárias nos Planos Municipais de Redução de Riscos. (BROLLO; FERREIRA, 2016, p.21)

Nessa etapa é realizada a análise, caracterização e dimensionamento das áreas de risco de inundação, deslizamento e solapamento, classificadas segundo o tipo e grau de risco, bem como a análise, quantificação e caracterização das famílias moradoras dessas áreas, segundo perfis demográficos, socioeconômicos e habitacionais (SÃO PAULO - CIDADE, 2014).

c) Setorização de risco alto e muito alto.

A partir de 2012 iniciou-se em âmbito nacional (...) visando subsidiar os sistemas de alarme e alerta dos municípios e atender às demandas dos órgãos federais (...). No Estado de São Paulo esses trabalhos têm sido elaborados pela CPRM e pela Coordenadoria Estadual de Defesa Civil (CEDEC) (BROLLO; FERREIRA, 2016, p.21).

d) Mapeamento da Suscetibilidade de Escorregamento e Inundação.

A PNPDEC alterou o Estatuto das Cidades, tornando obrigatória a elaboração de carta geotécnica como ferramenta de planejamento urbano, de infraestrutura, de gestão de recursos hídricos e de ocupação de uso do solo. (...) As cartas de suscetibilidade a movimentos gravitacionais de massa e a inundações geradas mostram uma classificação relativa (alta, média, baixa) apoiada em um modelo de abordagem em desenvolvimento, fundamentado inicialmente em fatores predisponentes relacionados aos terrenos, espacializáveis e obtidos por meio de compilação e tratamento de dados secundários (BROLLO; FERREIRA, 2016, p.21).

e) Plano Preventivo de Defesa Civil (PPDC) e Planos de Contingência voltados a escorregamentos e inundações.

Este Plano (o PPDC) entra em operação anualmente, no período de quatro meses de verão (dezembro a março) e envolve ações de monitoramento dos totais pluviométricos (chuvas) e da previsão meteorológica, além de vistorias de campo e atendimentos emergenciais com vistorias técnicas em áreas de risco. $\mathrm{O}$ objetivo principal é evitar a ocorrência de mortes, com a remoção 
preventiva e temporária da população que ocupa as áreas de risco, antes que os escorregamentos atinjam suas moradias. (...) Os Planos de Contingência são instrumentos de ação, que estabelecem os procedimentos a serem adotados pelos órgãos envolvidos na resposta a emergências e desastres quando da atuação direta ou indireta em eventos relacionados a estes desastres naturais. (...) A operação dos planos é regulamentada por Resoluções da Casa Militar, anualmente editadas, as quais especificam todas as regiões e municípios que operam o plano (BROLLO; FERREIRA, 2016, p.22).

\section{f) Campanha "Construindo Cidades} Resilientes".

Uma cidade resiliente é aquela que tem a capacidade de resistir, absorver e se recuperar de forma eficiente dos efeitos de um desastre e de maneira organizada prevenir que vidas e bens sejam perdidos. (...) Esta campanha, lançada no Brasil em 2013, faz parte da Estratégia Internacional para a Redução de Desastres (EIRD), da Organização das Nações Unidas (ONU). O objetivo (da campanha) é aumentar o grau de consciência e compromisso em torno das práticas de desenvolvimento sustentável, como forma de diminuir as vulnerabilidades e propiciar o bem-estar e segurança dos cidadãos. (...) No Brasil é uma iniciativa da Secretaria Nacional de Defesa Civil (SEDEC), do Ministério da Integração Nacional (MI), para sensibilizar governos e cidadãos para os benefícios de se reduzir os riscos por meio da implementação de 10 passos para construir cidades resilientes. (...) No Estado de São Paulo, a CEDEC tem incentivado os municípios a aderirem a esta campanha e, em conjunto com a Secretaria do Meio Ambiente, vem proporcionando o incremento na adesão à Campanha via Programa Município Verde Azul, que anualmente promove a medição da eficiência da gestão ambiental nos municípios paulistas (BROLLO; FERREIRA, 2016, p.23).

Brollo e Ferreira (2016) também avaliaram que os instrumentos de gestão de risco utilizados pelos municípios no Estado de São Paulo estão em evolução nos últimos 15 anos. Atualmente 402 municípios (62\% dos municípios do Estado) já foram atendidos por algum dos instrumentos de gestão existentes.

Os municípios devem elaborar, a partir do seu Plano Diretor, o mapeamento das áreas suscetíveis à ocorrência de desastres naturais, bem como o plano de contingência para a redução do risco. São esses instrumentos que permitem planejar, diagnosticar e buscar minimizar os problemas nessas áreas.

\section{O Plano Diretor do Município de São Paulo}

O Plano Diretor Estratégico do Município de São Paulo, Lei Municipal no 16.050/2014 (SÃO PAULO - CIDADE, 2014) prevê objetivos e estratégias de ordenamento territorial para áreas homogêneas definidas como macrozonas e macroáreas. A Macrozona de Estruturação e Qualificação Urbana, engloba a maior parte da área urbanizada, e as planícies fluviais dos rios Tietê, Pinheiros e Tamanduateí, do qual o Córrego Ipiranga é afluente (Figura 2). Dentre os objetivos gerais dessa área destaca-se o Art. $10, \S 2^{\circ}, \mathrm{I}$ :

a promoção da convivência mais equilibrada entre a urbanização e a conservação ambiental, entre mudanças estruturais provenientes de grandes obras públicas e privadas e as condições de vida dos moradores.

Quando se refere à rede hídrica do município, o Art. 25 cita objetivos urbanísticos e ambientais estratégicos relacionados à sua recuperação e proteção:

I - ampliar progressivamente as áreas permeáveis ao longo dos fundos de vales e cabeceiras de drenagem, as áreas verdes significativas e a arborização, especialmente na Macrozona de Estruturação e Qualificação Urbana, para minimização dos processos erosivos, enchentes e ilhas de calor;

II - ampliar os parques urbanos e lineares para equilibrar a relação entre o ambiente construído e as áreas verdes e livres e garantir espaços de lazer e recreação para a população;

III - integrar as áreas de vegetação significativa de interesse ecológico e paisagístico, protegidas ou não, de modo a garantir e fortalecer sua proteção e preservação e criar corredores ecológicos; IV - proteger nascentes, olhos d'água, cabeceiras de drenagem e planícies 
aluviais;

$\mathrm{V}$ - recuperar áreas degradadas, qualificando-as para usos adequados;

VI - articular, através de caminhos de pedestres e ciclovias, preferencialmente nos fundos de vale, as áreas verdes significativas, os espaços livres e os parques urbanos e lineares;

VII - promover, em articulação com o Governo Estadual, estratégias e mecanismos para disciplinar a drenagem de águas subterrâneas.

Figura 2 - Localização da Macrozona de Estruturação e Qualificação Urbana dos rios Tietê, Pinheiros e Tamanduateí, no município de São Paulo/SP.

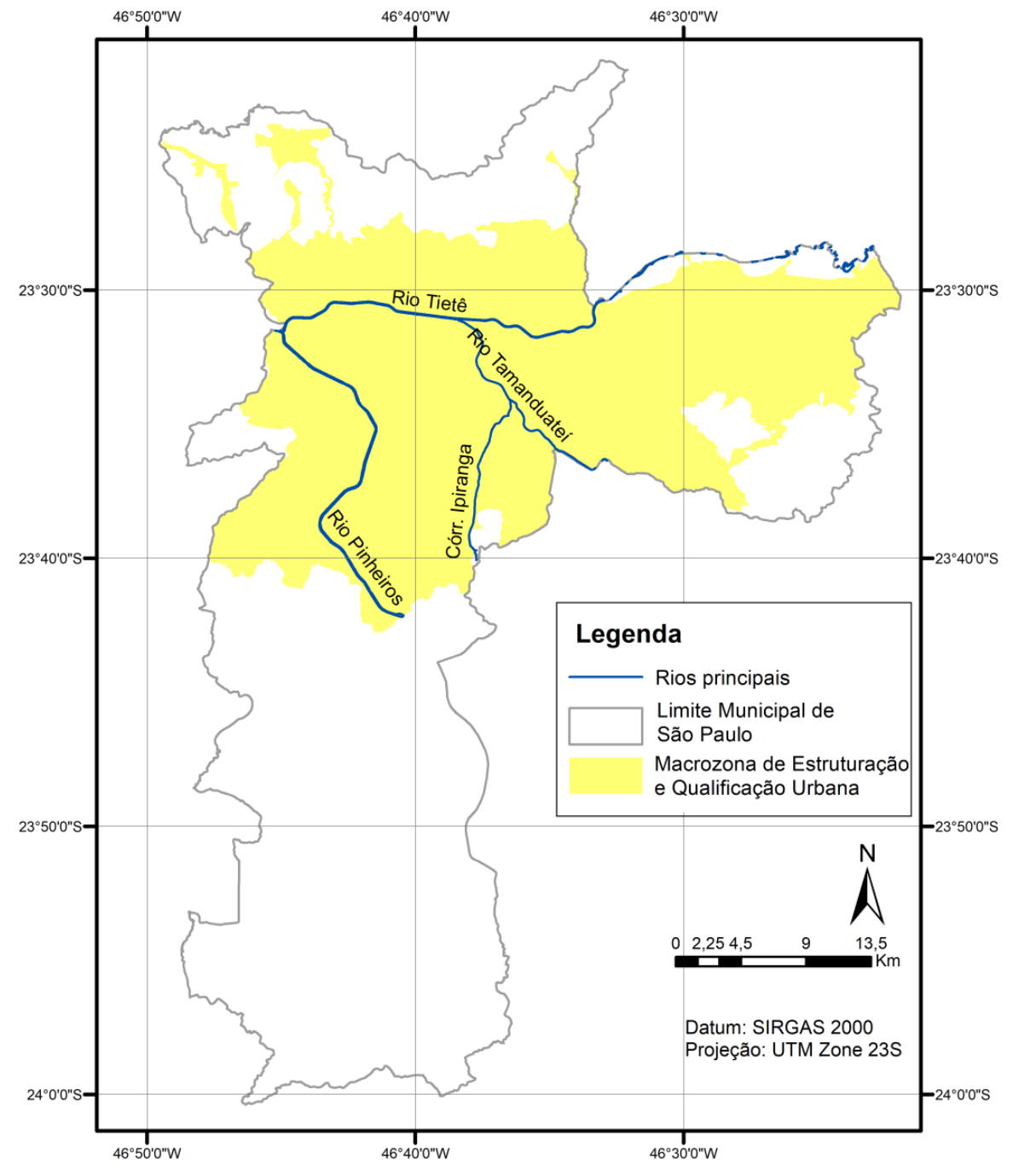

Org: Autores, 2020.

No capítulo que trata da regulação do parcelamento, uso e ocupação do solo e da paisagem urbana (Art. 27), destacam-se os objetivos de:

(...) IV - estabelecer parâmetros e mecanismos relacionados à drenagem das águas pluviais, que evitem o sobrecarregamento das redes, alagamentos e enchentes;

V - criar parâmetros de ocupação do solo relacionados a aspectos geológicos, geotécnicos e hidrológicos; (...)

Ainda destaca a necessidade de apresentar estratégias (Art. 29) para o controle da(s):

(...) XII - fragilidade ambiental e da aptidão física à urbanização, especialmente as áreas suscetíveis à ocorrência de deslizamentos, inundações ou processos geológicos e hidrológicos correlatos 
indicados no Mapeamento de Áreas de Risco e na Carta Geotécnica do Município de São Paulo; (...)

XIV - áreas de preservação permanente; (...)

Dessa forma, avalia-se que o Plano Diretor prevê possibilidades para a readequação de áreas de risco à inundação, citadas em diversos artigos.

\section{A OCUPAÇÃO DAS VÁRZEAS E AS INUNDAÇÕES NA BACIA DO CÓRREGO IPIRANGA}

$\mathrm{Na}$ bacia do Córrego Ipiranga, as primeiras intervenções que se tem registro datam do período entre 1910 e 1920, posteriores às obras dos jardins do Parque da Independência que são de 1907, quando se concluiu a canalização a céu aberto no trecho a jusante, como parte das obras comemorativas do Centenário da Independência, nas áreas próximas ao Museu Paulista, também conhecido como Museu do Ipiranga, localizado no Parque da Independência (Figura 3). Na década de 1930, além dessas intervenções, o trecho entre o bairro Chácara Inglesa e Bosque da Saúde, no médio curso, também apresentava retificação e cruzamentos de vias sobre o Córrego.

Figura 3 - Obras para retificação do Riacho do Ipiranga (1910-1920), ao fundo, o Museu Paulista, popularmente conhecido como Museu do Ipiranga.

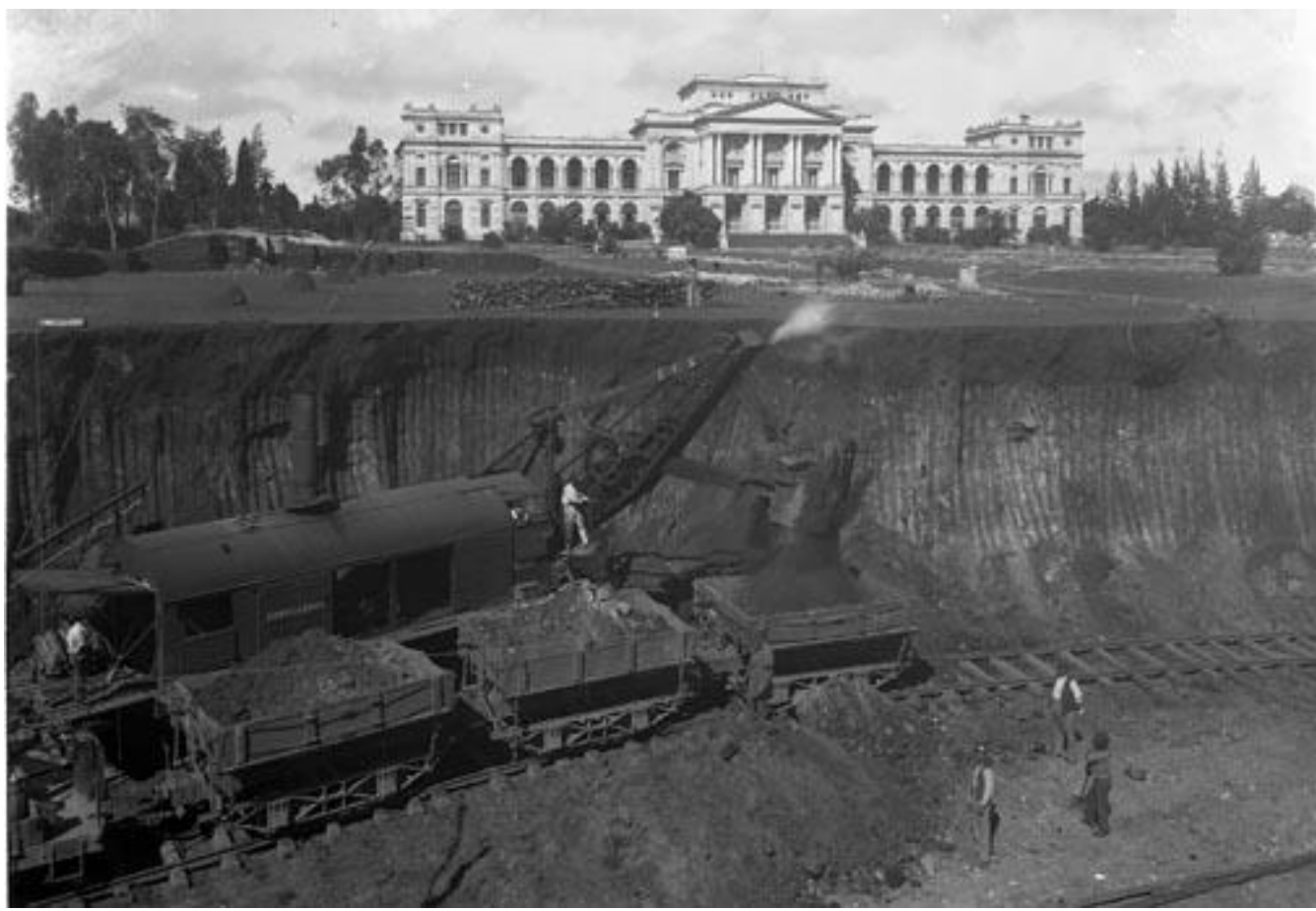

Fonte: Acervo Fotográfico do Museu da Cidade de São Paulo. PMSP (2018).

Travassos (2004) destaca que o Plano de Avenidas do Município de São Paulo, datado de 1957, determinou a ocupação dos fundos de vale por sistemas viários, e indicava a canalização de diversos córregos, e dentre esses, o Córrego Ipiranga. O plano não contemplava obras para o controle das inundações e não havia proposta de uso para as áreas às margens.

A intervenção ocorreu nas décadas de 1960 e 1970, com a retificação e canalização aberta da extensão total do curso principal para a instalação da Avenida Água Funda em ambas as margens do Córrego, inaugurada em 1967
(Figura 4). Hoje a avenida é denominada Av. Dr. Ricardo Jafet no trecho entre o Parque da Independência até a altura do Bairro da Chácara Inglesa. A partir desse trecho, a via é denominada como Av. Prof. Abraão de Morais, até o início da Rodovia dos Imigrantes.

A cada trecho em que o córrego era retificado e canalizado, poucos anos depois a ocupação urbana se adensava e consolidava no entorno. Entre as décadas de 1910 e 1970, praticamente todo o canal principal foi canalizado a céu aberto e as áreas regularizadas. Os afluentes foram canalizados em subterrâneo e somente os 
afluentes na área interna ao PEFI mantiveram suas condições originais.

Figura 4 - Vista aérea das obras para abertura da Avenida Água Funda (atual Av. Dr. Ricardo Jafet), e retificação do Córrego Ipiranga, no trecho em que corta o bairro de Vila São José, vista tomada em direção ao bairro de Vila Monumento 1970, São Paulo/SP.

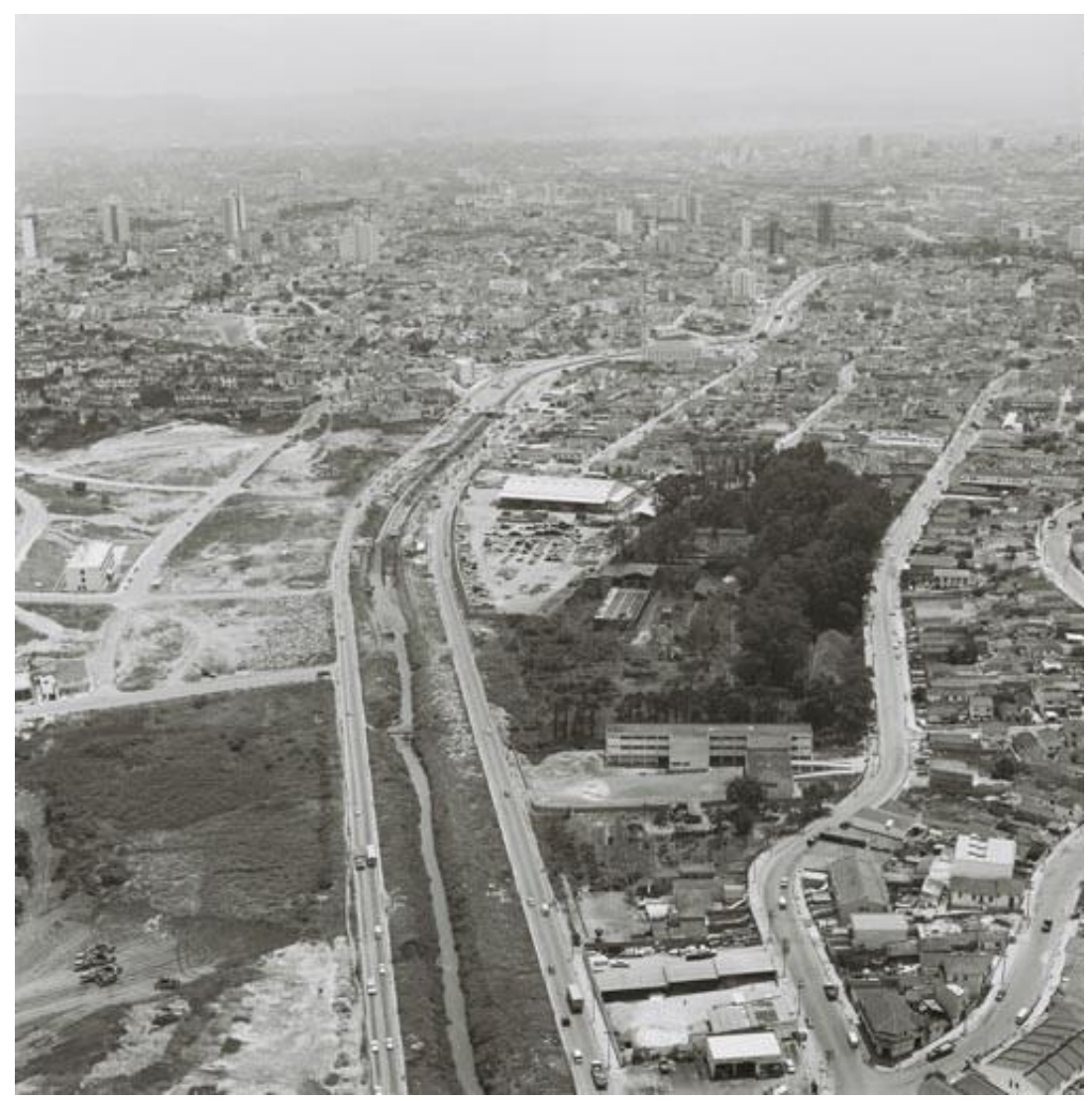

Fonte: Acervo Fotográfico do Museu da Cidade de São Paulo. PMSP (2018).

Destaca-se que na bacia existe apenas uma área com ocupação irregular em área pública, lindeira a um pequeno trecho de afluente não canalizado no limite com o PEFI, mas que não registra dados oficiais de ocorrência de inundações. No restante da bacia, em que há ocupações às margens do canal a céu aberto e sobre os afluentes canalizados subterrâneos, os loteamentos são regulares. Todos os registros de inundações são no entorno do canal principal, no trecho entre o médio curso e jusante.

\section{Pontos de inundação e registros de danos $e$ prejuizos}

De acordo com o levantamento de dados realizado por Santos e Amaral (2017) foram registrados 82 eventos de inundação na bacia no período entre 1965 a 2017, que totaliza 52 anos. Dessa forma, em média, ocorreu mais de uma inundação por ano na área da bacia do Córrego Ipiranga. Não foram encontradas notícias anteriores a 1965, uma vez que não havia ocupação urbana nas margens do córrego.

Para o levantamento de dados foram consultados os acervos digitais dos jornais Ipiranga News, Jabaquara News, Folha de São Paulo e o Estado de São Paulo, além dos dados institucionais obtidos junto ao Centro de Gerenciamento de Emergências da Prefeitura de São Paulo (CGE/PMSP) e ao Sistema de Alerta a Inundações do Estado de São Paulo, Departamento de Águas e Energia Elétrica, Fundação Centro Tecnológico de Hidráulica (SAISP/DAEE/FCTH). Os dados foram tabulados em ficha padrão, adaptado de IG (2009). Após análise estatística, os locais foram inseridos em um mapa de localização dos pontos de inundação, identificados em 31 endereços ou cruzamentos de vias (Figura 5).

Os danos e prejuízos registrados por década são apresentados na Tabela 1 . 
Tabela 1. Danos e prejuízos registrados em meios de comunicação, no período de 1965 a Julho de 2017, na Bacia do Córrego Ipiranga, São Paulo/SP.

\begin{tabular}{|c|c|c|c|c|}
\hline Década & Período & $\begin{array}{l}\text { Qtde de } \\
\text { eventos }\end{array}$ & Fonte & $\begin{array}{l}\text { Danos e prejuízos relatados } \\
\text { (conforme notícias) }\end{array}$ \\
\hline 1960 & $\begin{array}{l}1965 \text { a } 1969 \\
\text { (5 anos) }\end{array}$ & 7 & Estadão & $\begin{array}{l}\text { Água invade lojas e residências, } \\
\text { prejudica o comércio }\end{array}$ \\
\hline 1970 & $\begin{array}{l}1970 \text { a } 1979 \\
(10 \text { anos) }\end{array}$ & 6 & $\begin{array}{l}\text { Folha de São } \\
\text { Paulo }\end{array}$ & $\begin{array}{c}150 \text { famílias desabrigadas } \\
\text { Trânsito interrompido } \\
\text { Paralização de atividade industrial }\end{array}$ \\
\hline 1980 & $\begin{array}{l}1980 \text { a } 1989 \\
(10 \text { anos })\end{array}$ & 3 & Estadão & 60 pessoas desabrigadas \\
\hline 1990 & $\begin{array}{l}1990 \text { a } 1999 \\
(10 \text { anos) }\end{array}$ & 10 & $\begin{array}{l}\text { Folha de São } \\
\text { Paulo }\end{array}$ & $\begin{array}{c}\text { Ruas intransitáveis, avenidas } \\
\text { interditadas } \\
\text { Prejuízo em indústria } \\
16 \text { mil pessoas sem energia elétrica }\end{array}$ \\
\hline 2000 & $\begin{array}{l}2000 \text { a } 2009 \\
(10 \text { anos })\end{array}$ & 10 & $\begin{array}{l}\text { Folha de São } \\
\text { Paulo }\end{array}$ & $\begin{array}{c}1 \text { morte } \\
\text { Carros arrastados } \\
\text { Avenidas interditadas }\end{array}$ \\
\hline 2010 & $\begin{array}{l}2010 \text { a } 2017^{*} \\
(7,5 \text { anos })\end{array}$ & 46 & $\begin{array}{l}\text { Ipiranga } \\
\text { News } \\
\text { CGE }\end{array}$ & $\begin{array}{c}\text { Água invade casas, moradores } \\
\text { perdem móveis e documentos } \\
\text { Carros submersos } \\
\text { Avenidas intransitáveis }\end{array}$ \\
\hline
\end{tabular}

Org.: Autores (2019).

No intervalo de quase 30 anos, entre a década de 1980 e 2010 , foram gastos cerca de $\mathrm{R} \$ 114,6$ milhões (valores não corrigidos) em medidas estruturais na Bacia do Córrego Ipiranga.

Em 2017 se iniciaram as obras para contenção de inundações com a construção de um piscinão com dois compartimentos e capacidade de armazenamento de $200 \mathrm{mil} \mathrm{m}^{3} \mathrm{e}$ desassoreamento de uma lagoa para reservatório de cheias com capacidade de armazenamento de $100 \mathrm{mil} \mathrm{m}^{3}$. As obras estão orçadas em $\mathrm{R} \$ 160$ milhões, com término inicialmente previsto para 2019.

De acordo com estudos da PMSP (2014) esses reservatórios foram concebidos com a função de diminuir as vazões de cheia no trecho em médio curso do Córrego Ipiranga, que apresentou maiores recorrências de inundações nos últimos anos. Entretanto, o estudo também aponta que, devido a ocupação do fundo de vale pelas avenidas e pela densa urbanização, não foram localizadas outras áreas que pudessem minimizar as vazões no trecho jusante sem a desapropriação de áreas particulares.

Observa-se que o trecho de médio curso também apresenta maior impacto econômico das inundações na mobilidade urbana e nas atividades comerciais, que predominam no local.

\section{CONSIDERAÇÕES FINAIS}

Conforme avaliado no estudo de caso, as inundações na bacia ocorrem desde a década de 1960, quando se retificou e canalizou o Córrego Ipiranga. Nessa mesma época, com a inauguração da avenida Água Funda, atualmente Av. Dr. Ricardo Jafet, que liga o centro à zona sul, construída às margens do córrego, as áreas de entorno foram ocupadas e propiciou a instalação de comércios, indústrias e residências, consideradas como passivos ambientais a partir do Código Florestal (Lei ${ }^{\circ}$ 4.771/1965).

As diversas medidas estruturais empregadas, até o momento, não foram suficientes para prevenir os acidentes e prejuízos. Em alguns pontos, as inundações ocorrem até mais do que uma vez ao ano e são registradas perdas materiais e danos relacionados à saúde. Não foram verificadas na bacia a existência de medidas não estruturais, tais como: sistemas de bioretenção ou uso de pavimentos permeáveis. 
Figura 5 - Pontos de inundação na Bacia do Córrego Ipiranga, Município de São Paulo/SP

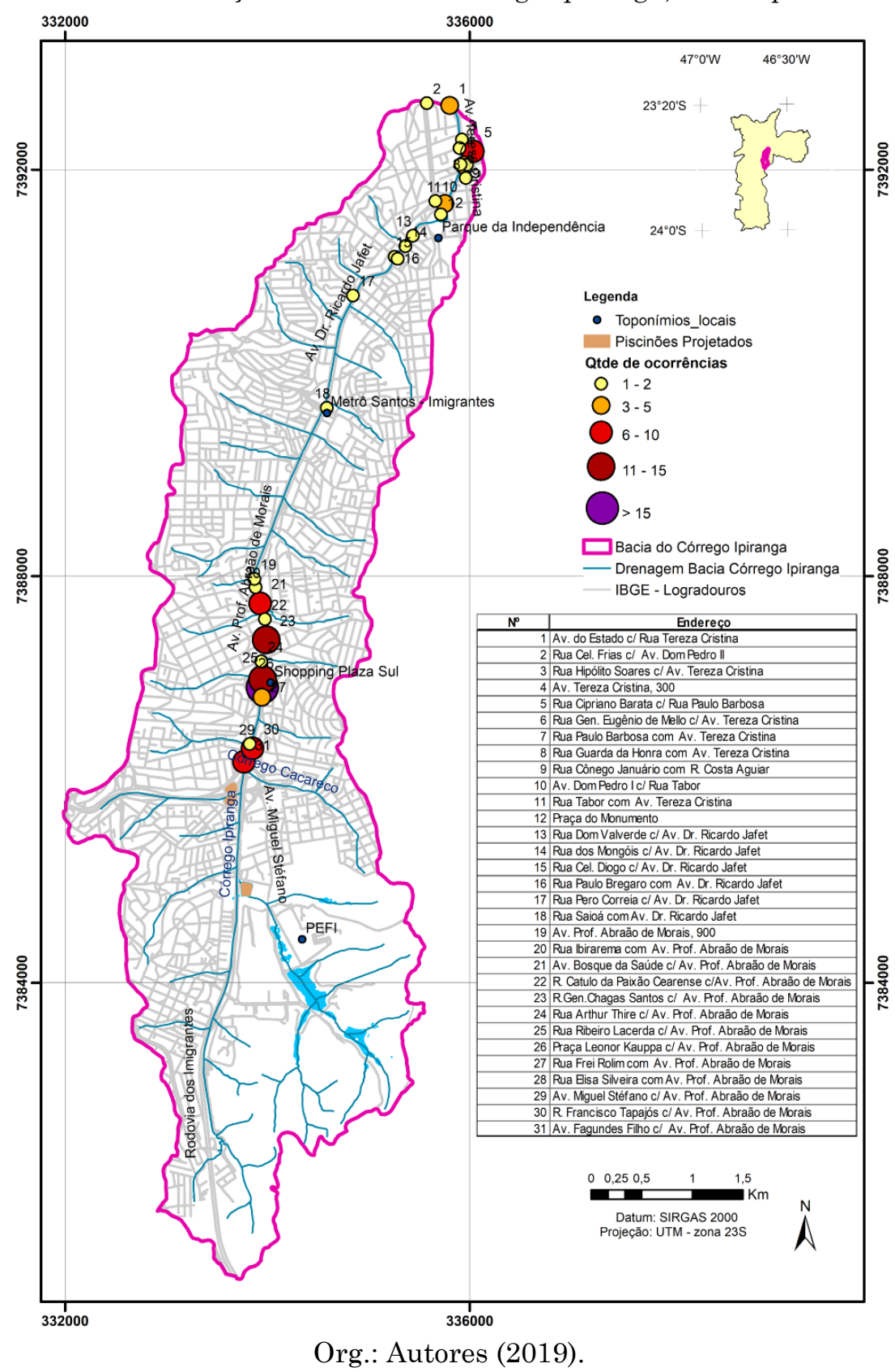

Desta forma, considera-se que medidas não estruturais podem ser empregadas concomitantemente às medidas estruturais já em andamento na Bacia do Córrego Ipiranga, de forma a minimizar os problemas econômicos, ambientais e sociais, e também para instruir a população quanto à convivência com o risco para que possam evitar novas perdas de vidas e de bens.

Apesar da existência de legislação que proibia a ocupação urbana nas áreas de preservação permanente ao longo dos cursos d'água, as várzeas e os fundos de vale foram ocupados e tornaram-se áreas regularizadas.

A sobreposição de legislações, que colocou em dúvida a sua devida aplicação em áreas urbanas, também se constituiu em uma vulnerabilidade que permitiu o avanço à ocupação das planícies. A implantação do Plano de Avenidas em São Paulo viabilizou e não regulamentou restrições para o uso dos fundos de vale.

Portanto, a cada curso d'água retificado ou canalizado, novos terrenos eram liberados para a ocupação, que ocorria rapidamente. A partir da ocupação das várzeas, surgiram as áreas de risco à inundação. A legislação se adequou a tratar da então gestão dos riscos, criando instrumentos e órgãos que buscam identificar e mitigar os problemas associados. Entretanto, nenhuma 
legislação buscou obrigatoriamente readequar as áreas de várzea à sua função original, que é armazenar as águas nos eventos de inundação para promover posteriormente o escoamento.

O Plano Diretor do Município de São Paulo tem como um dos seus objetivos gerais a promoção da convivência mais equilibrada entre a urbanização e a conservação ambiental. Uma vez que as áreas já estão ocupadas, do ponto de vista econômico, dificilmente haverá uma mudança de uso. Entretanto, deve-se reconhecer, que do ponto de vista de sua função natural, as várzeas serão sempre áreas sujeitas à inundação.

Os instrumentos de gestão de risco atuais têm se pautado na prevenção e no planejamento. Em áreas recorrentemente atingidas, é importante que os estudos de bacias hidrográficas indiquem como intervenção a desocupação de áreas que exponham populações vulneráveis e que proponham mudanças de uso nas áreas sob constante perigo de inundação. Cabe destacar que essas áreas, se desocupadas, devem ter logo uma proposta de novo uso, ou serão novamente ocupadas indevidamente pela população. Para tal, é necessário que as esferas governamentais sejam obrigadas a executar as medidas indicadas pelos estudos. Em se optar por medidas ambientais, são promovidas também melhoras na qualidade de vida.

Entretanto, essa alternativa apresenta alto custo econômico de implantação, além de implicar em problemas sociais devido à necessidade de realocações de imóveis, comércios e viário de grande tráfego. Portanto, as soluções são bem mais complexas e necessitam de uma nova visão de planejamento estratégico, não só para resolver de forma local, mas regional.

\section{AGRADECIMENTOS}

Ao CGE/PMSP, SAISP/DAEE/FCTH e a Estação Meteorológica do IAG/USP pela disponibilização dos dados que possibilitaram as análises realizadas nesse trabalho.

\section{REFERÊNCIAS}

AMARAL, R.; RIBEIRO, R.R. Inundações e enchentes. In: TOMINAGA, L. K.; SANTORO, J.; AMARAL, R. (Org.) Desastres naturais: conhecer para prevenir. São Paulo:
Instituto Geológico, 2009.

ANELLI, R. L. S. Uma nova cidade para as águas urbanas. Estudos Avançados v. 29, n.84, p. 69-84, 2015. https://doi.org/10.1590/S010340142015000200 005

BRASIL. Lei $\mathrm{n}^{\circ} \mathbf{4 . 7 7 1}$ de 15 de setembro de 1965. Institui o Novo Código Florestal. Disponível em: <https://www2.camara.leg.br/legin/fed/lei/196 0-1969/lei-4771-15-setembro-1965-369026publicacaooriginal-1-pl.html>. Acesso em 12 nov. 2016.

BRASIL. Lei $n^{\circ}$ 6.766 de 19 de dezembro de 1979 (Lei Lehmann). Dispõe sobre o parcelamento do solo urbano e dá outras providências. Disponível em: <http://www.planalto.gov.br/ccivil_03/LEIS/L 6766.htm>. Acesso em 17 fev. 2020.

BRASIL. Lei $n^{\circ} 6.938$ de 31 de agosto de 1981. Dispõe sobre a Política Nacional do Meio Ambiente, seus fins e mecanismos de formulação e aplicação, e dá outras providências. Disponível em: <http://www.planalto.gov.br/ccivil_03/leis/1693 8.htm>. Acesso em 20 jun. 2019.

BRASIL. Lei $\mathbf{n}^{\circ} \mathbf{9 . 6 0 5}$ de 12 de fevereiro de 1998. Dispõe sobre as sanções penais e administrativas derivadas de condutas e atividades lesivas ao meio ambiente, e dá outras providências. Disponível em: <http://www.planalto.gov.br/ccivil_03/Leis/L9 605.htm>. Acesso em 20 jun. 2019.

BRASIL. Resolução CONAMA n 303 de 20 de março de 2002. Dispõe sobre parâmetros, definições e limites de áreas de Preservação Permanente. Disponível em: <http://www2.mma.gov.br/port/conama/legiab re.cfm?codlegi=299>. Acesso em 21 jun. 2019.

BRASIL. Lei no 12.608 de 10 de abril de 2012. Institui a Política Nacional de Proteção e Defesa Civil - PNPDEC; dispõe sobre o Sistema Nacional de Proteção e Defesa Civil SINPDEC e o Conselho Nacional de Proteção e Defesa Civil - CONPDEC; autoriza a criação de sistema de informações e monitoramento de desastres; altera as Leis nos 12.340 , de 1 o de dezembro de 2010, 10.257, de 10 de julho de 2001, 6.766, de 19 de dezembro de 1979, 8.239, de 4 de outubro de 1991, e 9.394, de 20 de dezembro de 1996; e dá outras providências. Disponível

em: <http://www.planalto.gov.br/ccivil_03/_Ato201 1-2014/2012/Lei/L12608.htm>. Acesso em 12 nov. 2016.

BROLLO, M. J.; FERREIRA, C. J. Gestão de riscos de desastres devido a fenômenos 
geodinâmicos no Estado de São Paulo: Cenário 2000-2015. Boletim do Instituto Geológico no 67. São Paulo: IG / SMA, 2016. 72p. Disponível

em:

<http://igeologico.sp.gov.br/files/2016/10/boleti m_IG_vol_67.pdf>.

CARVALHO, C. S.; MACEDO, E. D.; OGURA, A. T. Mapeamento de riscos em encostas e margem de rios. Brasília: Ministério das Cidades, 2007.

CUNHA, M. I. R. Inundações brasileiras - uma questão de política pública. Congresso virtual brasileiro-Administração, Vol. 9, 2012. Disponível em: <http://convibra.org/upload/paper/2012/38/201 2_38_4784.pdf>. Acesso em 12 nov. 2016.

CUSTÓDIO, V. A persistência das inundações na Grande São Paulo. Tese de Doutorado, Departamento de Geografia, FFLCH, Universidade de São Paulo, 2002.

IG - INSTITUTO GEOLÓGICO (2009) - Banco de Dados Históricos de Desastres Naturais Relacionados a Eventos Climáticos na Baixada Santista,

http://200.144.28.233/dnbs/busca.php, acesso em 16 fev. 2015.

JHA, A.K.; BLOCH, R.; LAMOND, J. Cidades e Inundações - um guia para a gestão integrada do risco de inundação urbana para o século XXI. Um resumo para os formuladores de políticas. Washington, D.C.: The World Bank, GFDRR, 2012. Disponível em: <http://documents.worldbank.org/curated/en/9 27951468152965134/Cidades-e-

Inunda\%C3\%A7\%C3\%B5es-Um-guia-para-aGest\%C3\%A3o-Integrada-do-Risco-de-

Inunda $\% \mathrm{C} 3 \% \mathrm{~A} 7 \% \mathrm{C} 3 \% \mathrm{~A} 30-U r b a n a-p a r a-0-$

S\%C3\%A9culo-XXI>. Acesso em: 12 nov. 2016.

KANASHIRO, W. H. Uma nova proposta para a macrodrenagem do Rio Tietê. In: Revista Engenharia $\mathbf{n}^{\mathbf{0}}$ 613, p. 80-85, 2013. Disponível em: <https://issuu.com/www.viapapel.com.br/docs/ 613_baixa>. Acesso em: 16 jan. 2019.

PMSP - PREFEITURA DA CIDADE DE SÃO PAULO, Obras de controle de inundações na Bacia do Riacho do Ipiranga. Estudo de Viabilidade Ambiental (EVA), Caracterização do empreendimento, Volume 1, 2014.

PMSP - PREFEITURA DA CIDADE DE SÃO PAULO - Acervo Fotográfico do Museu da Cidade de São Paulo, 2018. Disponível em: $<$ http://www.acervosdacidade.prefeitura.sp.go v.br/PORTALACERVOS/ExibirItemAcervo.as px?id=470935>. Acesso em 29 set 2018 .

RODRIGUES, C. Atributos ambientais no ordenamento territorial urbano. O exemplo das planícies fluviais na Metrópole de São Paulo. GEOUSP Espaço E Tempo (Online), v. 19, n. 2, p. 324-347, 2015. Disponível em: <https:/www.revistas.usp.br/geousp/article/vi ew/102805>. Acesso em: 24 fev. 2020.

ROLNIK, R. Lei e Política: a construção dos territórios urbanos. Projeto História: Revista do Programa de Estudos PósGraduados de História, v. 18, 1999.

SANTOS, A. P.; AMARAL, R. Levantamento histórico de dados de inundação do córrego Ipiranga - São Paulo/SP, Caderno de Resumos do $7^{\circ}$ Seminário de Iniciação Cientifica PIBIC. São Paulo: Instituto Geológico, 2017. Disponível em: <http://igeologico.sp.gov.br/files/2018/02/RES UMOS_7-SIC-IG_2016.pdf>. Acesso em 18 ago. 2018

SÃO PAULO (CIDADE). Lei $\mathbf{n}^{\circ}$ 16.050, de 31 de julho de 2014. Aprova a Política de Desenvolvimento Urbano e o Plano Diretor Estratégico do Município de São Paulo e revoga a Lei $n^{0}$ 13.430/2002. Diário Oficial da Cidade de São Paulo de 01 ago. 2014. Disponível em: <gestaourbana.prefeitura.sp.gov.br/arquivos/ PDE...PDE_SUPLEMENTO-DOC.pdf $>$.

Acesso em: 02 abr. 2018.

SÃO PAULO (ESTADO). Lei no $\mathbf{1 3 . 7 9 8}$, de 09 de novembro de 2009. Institui a Política Estadual de Mudanças Climáticas - PEMC. Disponível em: <https://www.al.sp.gov.br/repositorio/legislaca o/lei/2009/lei-13798-09.11.2009.html>. Acesso em: 05 abr. 2018.

SÃO PAULO (ESTADO). Decreto Estadual $\mathbf{n}^{\mathbf{0}}$ 57.512, de 11 de novembro de 2011. Institui o Programa Estadual de Prevenção de Desastres Naturais e de Redução de Riscos Geológicos e dá providências correlatas. Disponível em: <https://www.al.sp.gov.br/repositorio/legislaca o/decreto/2011/decreto-57512-

11.11.2011.html>. Acesso em: 05 abr. 2018.

SEABRA, O. C. D. L. Os meandros dos rios nos meandros do poder: Tietê e Pinheiros-valorização dos rios e das várzeas na cidade de São Paulo. Tese de Doutorado. São Paulo: USP/FFLCH, 1987.

SWISS RE Institute (2017) Natural catastrophes and man-made disasters in 2016: a year os widespread damages. Disponível em: $<$ http://institute.swissre.com/research/library/ NatCat_and_manmade_disasters_2016.html> . Acesso em 23 abr. 2017. 
TAVARES, A.C; SILVA, A.C.F. Urbanização, chuvas de verão e inundações: uma análise episódica. Climatologia e Estudos da Paisagem. Rio Claro. v. 3, n.1., 2008.

TRAVASSOS, L. R. F. C. A dimensão socioambiental da ocupação dos fundos de vale urbanos no Município de São Paulo. Dissertação de Mestrado. Programa de Pós-Graduação em Ciência Ambiental da USP (PROCAM/USP). São Paulo: PROCAM, 2004.

TUCCI, C. E. M. Drenagem urbana. Porto Alegre: ABRH- Editora UFRGS, 1ª Ed., 1995.

TUCCI, C. E. M. Hidrologia Ciência e Aplicação. Porto Alegre: ABRH- Editora UFRGS, $3^{\text {a }}$ ed., p. 621-658, 2002.

TUCCI, C. E. M. Inundações e drenagem urbana. Inundações Urbanas na América do Sul, Porto Alegre: ABRH, p. 45-129, 2003.

UNISDR - United Nations Office for Disaster Risk Reduction. Terminology. Disponível em: <https://www.unisdr.org/we/inform/terminolo gy>. Acesso em 14 mai. 2018. 